\title{
Analysis of Aerosol Emission and Hazard Evaluation of Electrical Discharge Machining (EDM) Process
}

\author{
Mathew JOSE ${ }^{1}$, S. P. SIVAPIRAKASAM ${ }^{1 *}$ and M. SURIANARAYANAN ${ }^{2}$ \\ ${ }^{1}$ Department of Mechanical Engineering, National Institute of Technology, Tiruchirappalli - 620 015, India \\ ${ }^{2}$ Cell for Industrial Safety and Risk Analysis, Central Leather Research Institute, Adyar, Chennai, India
}

Received July 18, 2008 and accepted December 7, 2009

\begin{abstract}
The safety and environmental aspects of a manufacturing process are important due to increased environmental regulations and life quality. In this paper, the concentration of aerosols in the breathing zone of the operator of Electrical Discharge Machining (EDM), a commonly used non traditional manufacturing process is presented. The pattern of aerosol emissions from this process with varying process parameters such as peak current, pulse duration, dielectric flushing pressure and the level of dielectric was evaluated. Further, the HAZOP technique was employed to identify the inherent safety aspects and fire risk of the EDM process under different working conditions. The analysis of aerosol exposure showed that the concentration of aerosol was increased with increase in the peak current, pulse duration and dielectric level and was decreased with increase in the flushing pressure. It was also found that at higher values of peak current $(7 \mathrm{~A})$ and pulse duration $(520 \mu \mathrm{s})$, the concentration of aerosols at breathing zone of the operator was above the permissible exposure limit value for respirable particulates $\left(5 \mathrm{mg} / \mathrm{m}^{3}\right)$. HAZOP study of the EDM process showed that this process is vulnerable to fire and explosion hazards. A detailed discussion on preventing the fire and explosion hazard is presented in this paper. The emission and risk of fire of the EDM process can be minimized by selecting proper process parameters and employing appropriate control strategy.
\end{abstract}

Key words: EDM, Aerosol, HAZOP, Fire hazard, Health hazard

\section{Introduction}

Electrical Discharge Machining (EDM) is one of the most extensively used nonconventional manufacturing processes for shaping harder materials and to generate complicated geometries. In this process, the heat generated due to an electric spark struck between a conductive work piece and a tool electrode is utilized to remove materials ${ }^{1)}$.

This process is carried out in a non-conductive dielectric fluid. The different dielectric fluids used in the EDM process include hydrocarbon oils, mineral oil and deionized water. High temperature and pressure in the discharge channel of the EDM can lead to

*To whom correspondence should be addressed.

E-mail: spshivam@nitt.edu the generation of a number of reaction-products in the dielectric. These reaction products can emit from the dielectric surface as aerosols or gases. The operators in the working environment are exposed to these toxic substances $^{2,3)}$. Generally, the exposure assessment is considered as a standard method for analysing the risk involved in this process ${ }^{4}$. The generation of hazardous substances from the EDM process is dependent on the rate of material removal, dielectric fluid, tool material and work piece material. However, the other factors that influence the amount and composition of emission are the process parameters such as peak current, voltage, pulse-on time, flushing pressure and dielectric level. Even though there are many reported studies ${ }^{5,6)}$ on production and quality aspects of the EDM processes, only few studies have been carried out considering the environmental, safety and health hazards and a systematic 
hazard profiling of the EDM process is not available in the literature. Moreover, the reported information on the experimental investigation of emission, while using kerosene as a dielectric medium in the EDM process is limited. Therefore, it is necessary to generate data on toxic releases with varying process parameters so that an appropriate control strategy can be applied. In this paper, measurement of aerosol concentration at the breathing zone of the operator was carried out by varying the process parameter of EDM process. Finally, the inherent hazards and fire risk of the EDM process were identified using a structured and exhaustive hazard evaluation technique known as Hazard and Operability Analysis (HAZOP).

\section{Materials and Methods}

\section{EDM machine and operating conditions}

The experiment was conducted using a conventional die sinking electrical discharge machine manufactured by Victory Electromech. The machine is typically used for machining small and medium sized components. The specifications of the EDM machine are presented in Table 1. The EDM machine was enclosed in a separate room of size $4 \mathrm{~m} \times 4 \mathrm{~m} \times 3 \mathrm{~m}$. A worst case scenario was considered in this study by measuring the concentration of aerosol at the breathing zone of the operator without providing local exhaust ventilation for the machining process. The work piece used in the study was mild steel piece of size $50 \mathrm{~mm} \times 50 \mathrm{~mm} \times 12 \mathrm{~mm}$. A copper rod of $25 \mathrm{~mm}$ diameter was used as the tool electrode. Commercially available kerosene was used as the dielectric fluid and side flushing was opted. The EDM process parameters varied in this study were peak current, pulse duration, level of dielectric above the spark location and flushing pressure. The gap voltage was kept constant at $100 \mathrm{~V}$ and duty factor was kept at 0.5 .

\section{Measurement of aerosol exposure}

The schematic diagram of experimental setup used for the measurement of aerosol exposure (concentration of aerosol in the work atmosphere) is shown in Fig. 1. A gravimetric analysis of the concentration of the aerosols in the breathing zone of the operator was carried out as per the standard procedures for analysis of "particulates not otherwise regulated - respirable" developed by NIOSH (method no 0600) ${ }^{7}$ ).

Aerosols emitted during the process were sampled using SKC universal air sampler with cyclone attachment (Fig. 2). Air velocity of this instrument was calibrated using a soap bubble meter. In this analysis the air velocity was kept at $2.5 \mathrm{l} / \mathrm{min}$. Air was actively pulled through glass fiber filter of $37 \mathrm{~mm}$ diameter
Table 1. Specifications of die sinking EDM machine

\begin{tabular}{cc}
\hline Parameter & Value \\
\hline Maximum current & $12 \mathrm{~A}$ \\
Open gap voltage & $135 \mathrm{~V}$ \\
Pulse duration & 2 to $520 \mu \mathrm{s}$ \\
Maximum flushing pressure & $1.5 \mathrm{~kg} / \mathrm{cm}^{2}$ \\
\hline
\end{tabular}

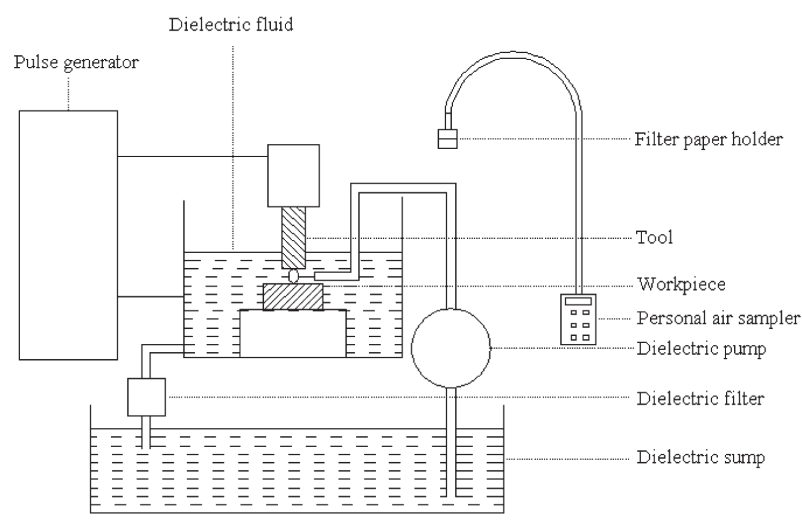

Fig. 1. Schematic diagram of experimental setup for aerosol sampling in EDM process.

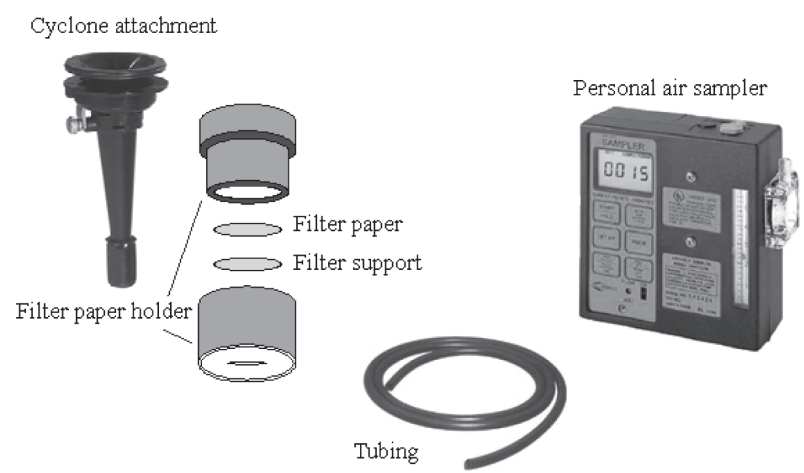

Fig. 2. Components of air sampling system for respirable particulates.

to collect airborne hazards in particulate form. The samples of the aerosol were taken at a sampling point of $200 \mathrm{~mm}$ vertical distance and $200 \mathrm{~mm}$ horizontal distance from the dielectric surface. The sampling point was representative of an operators breathing zone in the worst case. The sampling was carried out for a duration of $8 \mathrm{~h}$.

Weight of the filter paper was taken before and after sampling with a sensitive balance (accuracy $\pm 0.01 \mathrm{mg}$ ). The concentration of aerosols was calculated using the following equation.

$$
C_{A}=\frac{1,000 \times\left(w_{b}-w_{a}\right)}{v \times t}
$$


Where,

$\mathrm{C}_{\mathrm{A}}$ - concentration of aerosols $\left(\mathrm{mg} / \mathrm{m}^{3}\right)$

$\mathrm{w}_{\mathrm{a}}$ - weight of filter paper before sampling (mg)

$\mathrm{w}_{\mathrm{b}}$ - weight of filter paper after sampling (mg)

$\mathrm{v}$ - sampling speed $(1 / \mathrm{min})$

$\mathrm{t}$ - sampling duration (min)

\section{Hazard evaluation}

Various techniques are used in the industry to identify and evaluate the significance of hazardous situations found in process operations and activities. The commonly used techniques include Safety Review, Hazard and Operability Analysis (HAZOP), Checklist Analysis, Failure Modes and Effects Analysis (FMEA), WhatIf Analysis, Event Tree Analysis (ETA), Fault Tree Analysis (FTA), Human Reliability Analysis (HRA) etc. Among these techniques, HAZOP is used in this study to evaluate the hazards of EDM process because of the following reasons.

- The EDM process is continuously operated for a long period of time. A more detailed and better documented technique is needed for evaluating the process and operational deviations of continuously operated processes.

- EDM workstation has many mechanical and electrical controls viz., current, voltage, dielectric level, flushing pressure, pulse duration etc. The HAZOP is suitable for performing a systematic search for every conceivable deviation in these controls from its normal operation using a set of 'guidewords'.

- The perceived risk of the EDM process is high and available hazard information is inadequate. A highly structured and exhaustive hazard evaluation technique should be applied for such processes. HAZOP is the most structured method of hazard evaluation technique available.

Therefore, HAZOP is the most suitable method for identifying the hazards of EDM workstations due to process or operational deviations. The HAZOP developed by ICI in the 1960s, is a powerful tool for identifying all potential risks connected to operation of a process or activity. This technique uses a systematic methodology to examine carefully all possible operating deviations from design intention for each segment of which the equipment is constituted ${ }^{8)}$ by a team drawn from different areas of expertise.

The process and instrumentation diagram of EDM workstation is shown in Fig. 3. The objective of the HAZOP study was to identify the environmental and safety problems of this process. During the HAZOP study, possible deviations were generated by rigorous questioning, prompted by a series of "guidewords"

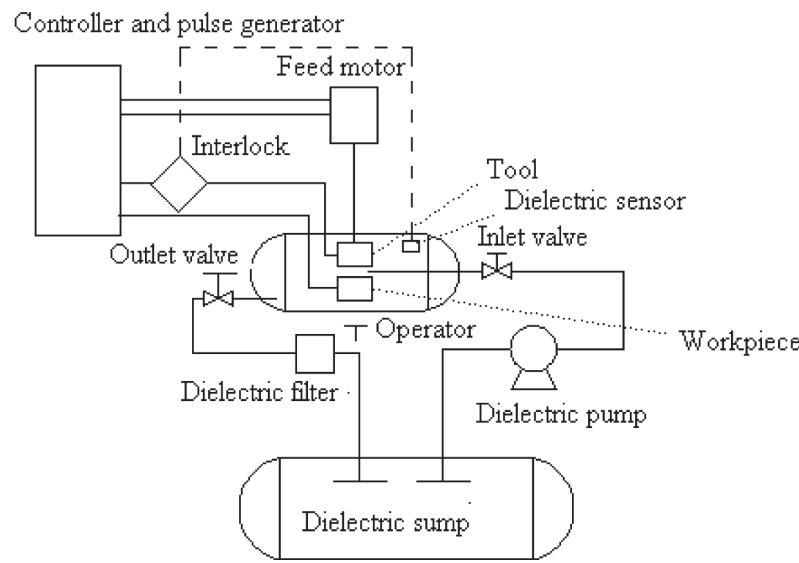

Fig. 3. Fig. 3. Process and instrumentation diagram of EDM workstation.

applied to each design intention of the machining process. After the guideword was matched with a parameter, a deviation was generated. Then the consequences and actions required to eliminate the problems were identified $^{9,10)}$. The HAZOP worksheet is presented in Fig. 4.

\section{Results and Discussion}

\section{Exposure analysis of aerosols}

Experimental results of aerosol concentration at the breathing zone for varying process parameters are presented in Table 2. It was observed that the aerosol concentration varied when any one of the process parameter was changed. This behavior showed that each parameter had a definite influence in aerosol emission.

\section{Effect of peak current}

Figure 5 shows the variation of aerosol concentration with the peak current, while keeping the pulse duration, dielectric level and flushing pressure at their higher values $\left(520 \mu \mathrm{s}, 80 \mathrm{~mm}\right.$ and $0.7 \mathrm{~kg} / \mathrm{cm}^{2}$ respectively). It was observed that with an increase in the peak current, aerosol concentration was increased. This was due to the fact that the increase in peak current increased the temperature in the processing location, which leads to higher material removal rate and subsequently to the generation of more fumes and particulate matters.

\section{Effect of pulse duration}

The influence of the pulse duration on aerosol concentration was identified by keeping the other parameters viz., peak current, dielectric level and flushing pressure at their higher values $\left(7 \mathrm{~A}, 80 \mathrm{~mm}\right.$ and $0.7 \mathrm{~kg} / \mathrm{cm}^{2}$ respectively). Figure 6 shows the variation of aerosol concentration with the pulse duration. It was evident 


\begin{tabular}{|c|c|c|c|c|}
\hline Guide Word & Deviation & Possible causes & Consequences & Action Required \\
\hline No & $\begin{array}{l}\text { No flow of } \\
\text { dielectric fluid }\end{array}$ & $\begin{array}{l}\text { 1. The pump fails } \\
\text { 2. Enough fluid not } \\
\text { available } \\
\text { 3. Line blockage } \\
\text { 4. Line fracture }\end{array}$ & $\begin{array}{l}\text { 1. Fire hazard } \\
\text { 2. Pump over heat, as } \\
\text { for (1) } \\
\text { 3. As for (1) and (2) } \\
\text { 4. Oil spillage, as for } \\
\text { (1) and (2) }\end{array}$ & $\begin{array}{l}\text { 1. Install alarm that } \\
\text { indicates the failure } \\
\text { of pump } \\
\text { 2.Install emergency } \\
\text { stop } \\
\text { 3. Ensure proper level } \\
\text { of dielectric fluid in } \\
\text { the tank }\end{array}$ \\
\hline Less & $\begin{array}{l}\text { Less flash point } \\
\text { of dielectric }\end{array}$ & $\begin{array}{l}\text { 5. Wrong selection } \\
\text { of dielectric fluid }\end{array}$ & 5.As for (1) & $\begin{array}{l}\text { 4. Select proper } \\
\text { dielectric fluid }\end{array}$ \\
\hline More & \begin{tabular}{|l|} 
More Dielectric \\
Temperature
\end{tabular} & $\begin{array}{l}\text { 6. Temperature rise } \\
\text { during machining } \\
\text { 7. High storage } \\
\text { temperature }\end{array}$ & $\begin{array}{l}\text { 6. Fire Hazard } \\
\text { Generation of vapors, } \\
\text { fumes and gases } \\
\text { 7. As for }(6)\end{array}$ & $\begin{array}{l}\text { 5. Thermostat for } \\
\text { monitoring the } \\
\text { temperature. } \\
\text { 6.Alarm to indicate } \\
\text { the rise of temperature }\end{array}$ \\
\hline As well as & $\begin{array}{l}\text { Unwanted } \\
\text { particles in } \\
\text { dielectric fluid }\end{array}$ & $\begin{array}{l}\text { 8. Improper } \\
\text { functioning of } \\
\text { filtering system }\end{array}$ & $\begin{array}{l}\text { 8. Toxic fumes in the } \\
\text { atmosphere, } \\
\text { Itritation to skin } \\
\text { demtmatitis }\end{array}$ & $\begin{array}{l}\text { 7. Ensure proper } \\
\text { filtering system } \\
\text { 8. Regular cleating } \\
\text { 9. Replace ment of } \\
\text { filters }\end{array}$ \\
\hline
\end{tabular}

a) Intention $\mathrm{A}$ - Transfer of dielectric from sump to dielectric tank

\begin{tabular}{|c|c|c|c|c|}
\hline Guide Word & Deviation & Possible causes & Consequences & Action Required \\
\hline No & $\begin{array}{l}\text { No flow of } \\
\text { dielectric through } \\
\text { filter }\end{array}$ & 9. Line blockage & $\begin{array}{l}\text { 9. Contamination of } \\
\text { dielectric fluid, } \\
\text { Irritation to skin } \\
\text { /dermatitis }\end{array}$ & $\begin{array}{l}\text { 10. Install alarm that } \\
\text { indicates the absence } \\
\text { of flow. } \\
\text { 11. Change the filter }\end{array}$ \\
\hline & $\begin{array}{l}\text { Malfunctioning of } \\
\text { filter }\end{array}$ & $\begin{array}{l}\text { 10. Filter used for } \\
\text { long duration }\end{array}$ & 10. As for (9) & 12.As for 11 \\
\hline Not & $\begin{array}{l}\text { Interlock not } \\
\text { working }\end{array}$ & 11. Circuit failure & 11. As for (6) & 13. Repair the interlock \\
\hline
\end{tabular}

b) Intention B: Flow of dielectric from EDM tank to sump

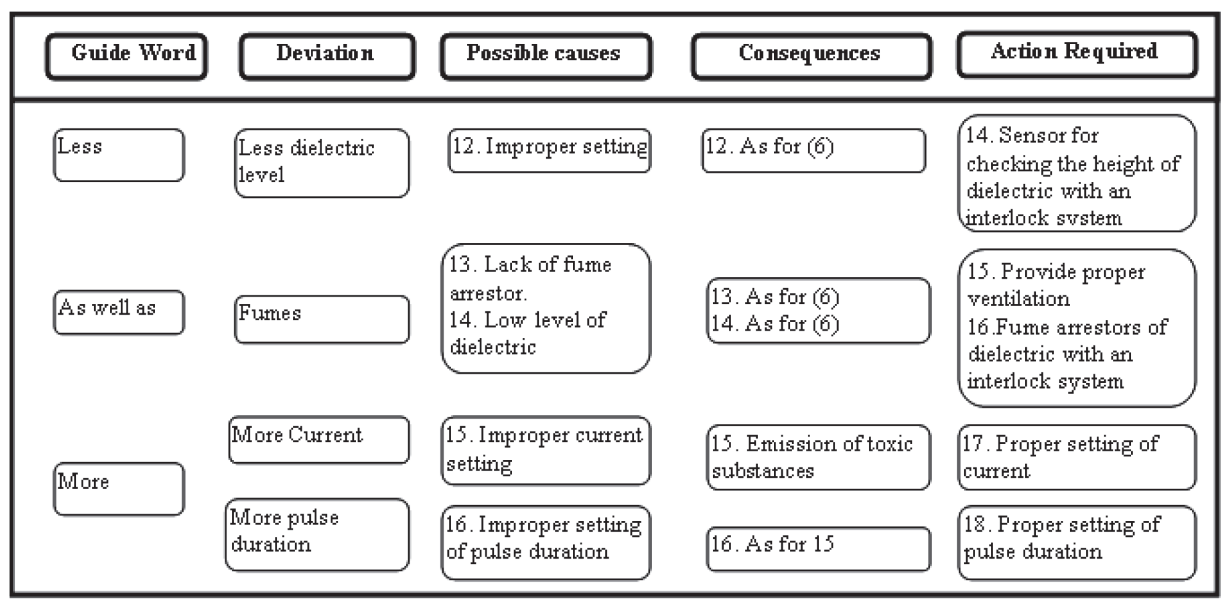

c) Intention C: Machining and pulse generation

\begin{tabular}{|c|c|c|c|c|}
\hline Guide Word & Deviation & Possible causes & Consequences & Action Required \\
\hline Less & Less ventilation & $\begin{array}{l}\text { 17. Not providing } \\
\text { proper ventilation }\end{array}$ & $\begin{array}{l}\text { 17. Contamination of } \\
\text { wotk atmosphere }\end{array}$ & $\left(\begin{array}{l}\text { 19. As for } 15 \\
\text { 20. Use of gas mask } \\
\text { system }\end{array}\right.$ \\
\hline
\end{tabular}

d) Intention D - General

Fig. 4. HAZOP work sheet. 
Table 2. Variation of aerosol concentration at breathing zone with process parameters

\begin{tabular}{rccccc}
\hline S1 No & Peak current (A) & $\begin{array}{c}\text { Pulse } \\
\text { duration }(\mu \mathrm{s})\end{array}$ & $\begin{array}{c}\text { Dielectric } \\
\text { level }(\mathrm{mm})\end{array}$ & $\begin{array}{c}\text { Flushing } \\
\text { pressure } \\
\left(\mathrm{kg} / \mathrm{cm}^{2}\right)\end{array}$ & $\begin{array}{c}\text { Aerosol } \\
\text { concentration } \\
\left(\mathrm{mg} / \mathrm{m}^{3}\right)\end{array}$ \\
\hline 1 & 7 & 520 & 80 & 0.7 & 5.19 \\
2 & 7 & 520 & 80 & 0.5 & 6.12 \\
3 & 7 & 520 & 80 & 0.3 & 7.2 \\
4 & 7 & 520 & 60 & 0.7 & 4.2 \\
5 & 7 & 520 & 40 & 0.7 & 3.3 \\
6 & 2 & 2 & 80 & 0.3 & 0.437 \\
7 & 2 & 2 & 60 & 0.3 & 0.435 \\
8 & 2 & 2 & 40 & 0.3 & 0.44 \\
9 & 7 & 250 & 80 & 0.7 & 1.83 \\
10 & 7 & 2 & 80 & 0.7 & 0.62 \\
11 & 4.5 & 520 & 80 & 0.7 & 2.89 \\
12 & 2 & 520 & & 0.7 & 0.56 \\
\hline
\end{tabular}

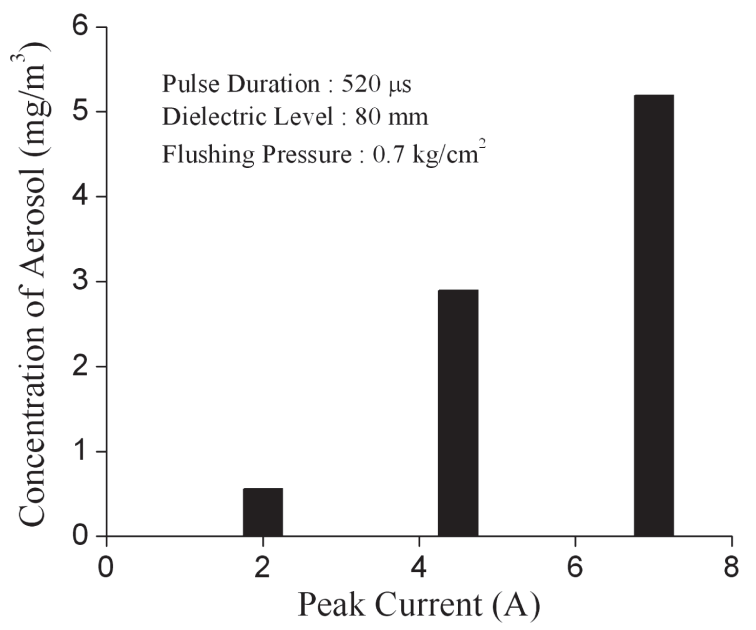

Fig. 5. Experimental results showing the effect of peak current on concentration of aerosol (respirable) at breathing zone of the operator.

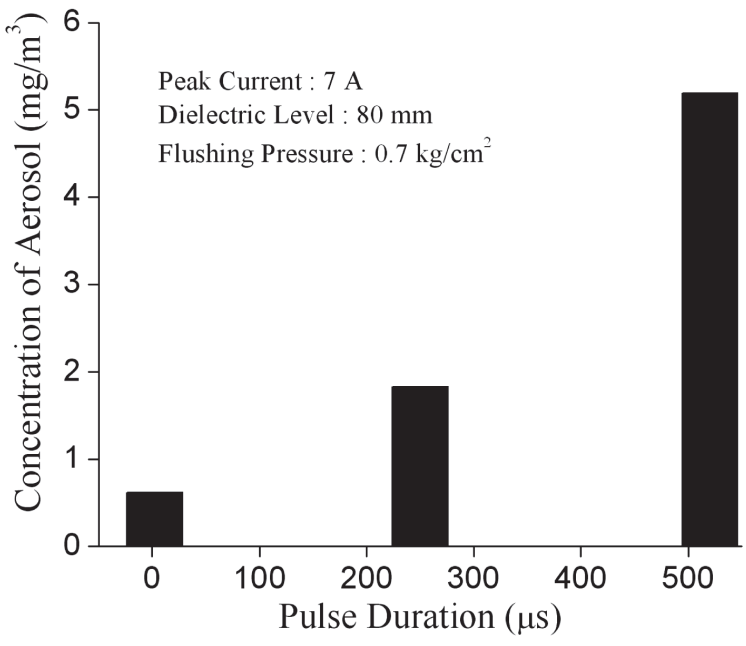

Fig. 6. Experimental results showing the effect of pulse duration on concentration of aerosol (respirable) at breathing zone of the operator. that the aerosol concentration increased with increase in pulse duration. This was due to the fact that an increase in the spark energy caused increase of temperature in the working gap.

\section{Effect of flushing pressure}

Figure 7 depicts the variation of aerosol concentration with change in the flushing pressure at higher values of peak current $(7 \mathrm{~A})$, pulse duration $(520 \mu \mathrm{s})$ and dielectric level $(80 \mathrm{~mm})$. It was seen that an increase in flushing pressure caused a decrease in aerosol concentration. This was due to the turbulence in the medium as a result of increased flushing pressure, which in turn influenced the diffusion of fumes in the dielectric fluid. It was also evident from the literature ${ }^{11,12)}$ that decrease in the flushing pressure could result in unstable machin- ing conditions and arcing around regions with high concentration of debris. Therefore, this study indicated that the generation of aerosol from the EDM process can be decreased by keeping the flushing pressure at a higher value. This is one of the significant findings of this study which has not been reported before.

\section{Effect of dielectric level}

Figure 8 shows the influence of dielectric level on the aerosol concentration at the breathing zone at higher values of peak current (7A), pulse duration $(520 \mu \mathrm{s})$ and flushing pressure $\left(0.7 \mathrm{~kg} / \mathrm{cm}^{2}\right)$. It was theoretically expected that the emission may decrease with an increase in the dielectric level i.e., the more dielectric fluid stands above the spark location, the more substances will be solved, precipitated and/or condensed 


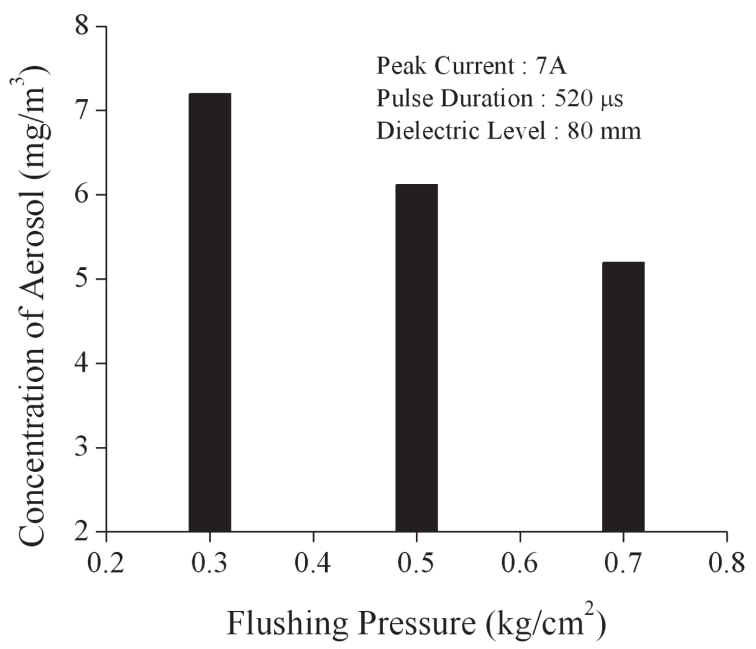

Fig. 7. Experimental results showing the effect of flushing pressure on concentration of aerosol (respirable) at breathing zone of the operator.

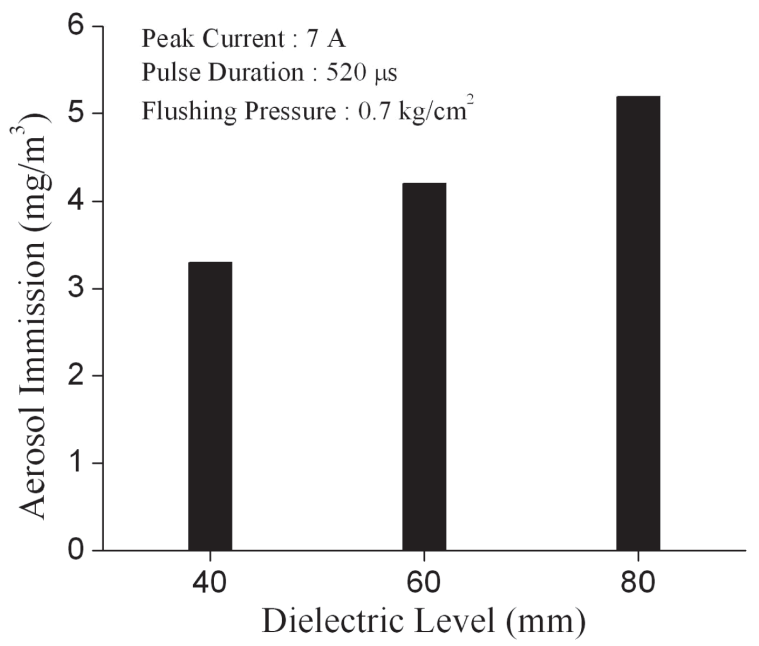

Fig. 8. Experimental results showing the effect of dielectric level on concentration of aerosol (respirable) at breathing zone of the operator (At high discharge energy).

in the dielectric fluid before actually emitting into the atmosphere. On the contrary, in this study, at higher peak current and pulse duration (higher discharge energy) the aerosol concentration showed an increasing tendency with increase in the dielectric level. This may be attributed to the fact that the higher discharge energy generated more heat content at the processing location resulting in a temperature gradient between the dielectric surface and spark location. It was hypothetically inferred that as the level of dielectric medium increased, more vapours condensed to form metallic particulates, which in turn increased the emission of particulates. However, this effect was not significant at lower discharge energy (peak current $=2 \mathrm{~A}$; pulse duration $=$ $2 \mu \mathrm{s}$; flushing pressure $=0.3 \mathrm{~kg} / \mathrm{cm}^{2}$ ) as shown in Fig. 9 .

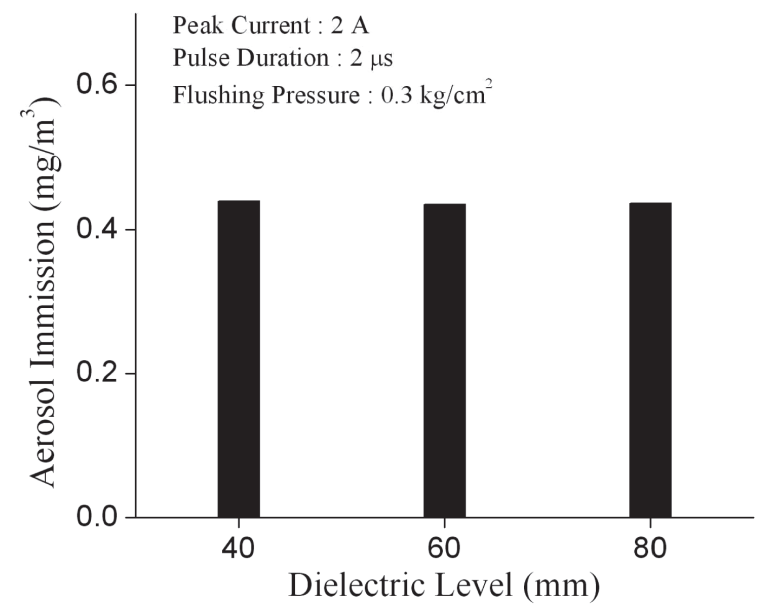

Fig. 9. Experimental results showing the effect of dielectric level on concentration of aerosol (respirable) at breathing zone of the operator (At low discharge energy).

This trend clearly indicated that the temperature generated at the spark location greatly affected the aerosol emission.

\section{Summary of HAZOP study}

The HAZOP study for the operation of EDM process has revealed the following:

1 An increase in the peak current or dielectric temperature increases the risk of fire hazard as well as toxic emission from the process. A worst case scenario such as explosion could be recognized when the dielectric temperature rose above the flash point of dielectric medium. The flash point is primarily used as an index of fire hazards for flammable and combustible fluids. At flash point temperature the fluid can evaporate to form a combustible mixture in the air, that will ignite and burn when exposed to a spark or flame. Therefore, it is cautioned that the temperature of dielectric medium should be operated below the flash point of the dielectric fluid.

2 A proper choice of dielectric medium with high flash point is very important while fixing the process parameter of the EDM process, as the present study indicated that less flash point dielectric medium has the risk of fire hazard.

3 Either decrease in the level of dielectric or no flow of dielectric fluid through pump could also cause fire hazard and increased emission. An alarming scenario could be foreseen when the dielectric level is below the spark location between tool and work piece. 
4 Contamination and long usage of dielectric medium will increase the emission rate and risk of fire.

The results of emission analysis and HAZOP study indicated that the EDM process is vulnerable to fire and emission hazards. The risk of these hazards can be minimized by selecting proper process parameters and employing appropriate precautionary measures. The fire hazard is associated with the use of hydrocarbon based dielectric fluids. Dielectric level is an important parameter to be monitored for safer operation. Therefore, it is suggested that level indicators or sensors linked with alarm can be used to ensure that dielectric level should reach the required height above the spark location. The fire risk can also be minimized if a dielectric liquid of high flash point is employed. Fire may also be caused due to an increase in the dielectric temperature and presence of electric spark near the dielectric surface. Open flames and electric sparks near the EDM workstation should be avoided completely and a spark arrester is recommended around the dielectric tank. Safety interlocks may be provided to shut down the process when the temperature of the dielectric rises to $15^{\circ} \mathrm{C}$ below its flash point ${ }^{3)}$. Proper earthing of the equipments and electric discharge machines should be done.
The EDM facility should be located in an isolated area and the building walls should be a fireproof one equipped with an automatic fire extinguishing system. Fire generated from the EDM process will come under class B, C and E. Dry powder extinguishers are most suitable in such situations.

There is a tendency in the present manufacturing industry to increase the discharge energy (current and pulse duration) to increase the production rate. However, this study revealed that the increase in peak current or pulse duration would lead to fire hazard and increased emission.

The experimental study showed that at higher values of peak current and pulse duration (7A and $520 \mu \mathrm{s}$ respectively), the concentration of aerosols was above the permissible exposure limit values of particulates $\left(5 \mathrm{mg} / \mathrm{m}^{3}\right)^{7}$. However, the limit values for particulates generated from EDM process are not available. Optimum values of process parameters need to be selected to minimize the emissions for a specific material removal. Further research is being carried out at our laboratory to identify the composition of fumes emitted. The health effects due to exposure of hazardous substances emitted from the EDM process are presented in Table 3 .

Table 3. Health effects of hazardous emissions

\begin{tabular}{|c|c|c|c|c|c|c|}
\hline \multirow[b]{2}{*}{ Component } & \multicolumn{3}{|c|}{ Exposure limits (ppm) } & \multirow[b]{2}{*}{ Roots of entry } & \multirow{2}{*}{$\begin{array}{c}\text { Carcinogenic } \\
\text { potential }\end{array}$} & \multirow[b]{2}{*}{ Health effects } \\
\hline & $\begin{array}{l}\text { OSHA } \\
\text { PEL }\end{array}$ & $\begin{array}{l}\text { NIOSH } \\
\text { REL }\end{array}$ & $\begin{array}{c}\text { STEL } \\
(15 \mathrm{~min})\end{array}$ & & & \\
\hline Benzene & 1 & 0.1 & 5 & $\begin{array}{l}\text { Ingestion, inhala- } \\
\text { tion absorption } \\
\text { through the skin }\end{array}$ & $\begin{array}{l}\text { Known human } \\
\text { carcinogen } \\
\text { (Leukemia) }\end{array}$ & $\begin{array}{l}\text { Drowsiness, dizziness, rapid heart rate, headaches, } \\
\text { tremors, confusion, unconsciousness, vomiting, irrita- } \\
\text { tion of the stomach, convulsions, anemia }{ }^{13)} \text {. }\end{array}$ \\
\hline Toluene & 200 & 100 & 300 & $\begin{array}{l}\text { Ingestion, inhala- } \\
\text { tion absorption } \\
\text { through the skin }\end{array}$ & $\begin{array}{l}\text { Not identified as } \\
\text { carcinogen }\end{array}$ & $\begin{array}{l}\text { Tiredness, confusion, weakness, drunken type actions, } \\
\text { memory loss, nausea, loss of appetite, hearing and } \\
\text { color vision loss, unconsciousness. High levels of } \\
\text { toluene may affect the nervous system and kidneys }{ }^{14)} \text {. }\end{array}$ \\
\hline $\begin{array}{c}\text { Ethyl } \\
\text { Benzene }\end{array}$ & 100 & 100 & 125 & $\begin{array}{l}\text { Ingestion, inhala- } \\
\text { tion absorption } \\
\text { through the skin }\end{array}$ & $\begin{array}{c}\text { Possible human } \\
\text { carcinogen }\end{array}$ & $\begin{array}{c}\text { Eye and throat irritation, Irreversible damage to the } \\
\text { inner ear and hearing and kidney damage have been } \\
\text { observed in animals }{ }^{15} \text {. }\end{array}$ \\
\hline Xylene & 100 & 100 & 150 & $\begin{array}{l}\text { Ingestion, inhala- } \\
\text { tion absorption } \\
\text { through the skin }\end{array}$ & $\begin{array}{l}\text { Not identified as } \\
\text { carcinogen }\end{array}$ & $\begin{array}{l}\text { Headaches, lack of muscle coordination, dizziness, } \\
\text { confusion, changes in one's sense of balance, irritation } \\
\text { of the skin, eyes, nose, and throat; difficulty in breath- } \\
\text { ing, problems with the lungs; delayed reaction time, } \\
\text { memory difficulties, stomach discomfort, changes in } \\
\text { the liver and kidneys, unconsciousness }{ }^{16)} \text {. }\end{array}$ \\
\hline PAH & $0.2 \mathrm{mg} / \mathrm{m}^{3}$ & $0.1 \mathrm{mg} / \mathrm{m}^{3}$ & 15 & $\begin{array}{l}\text { Ingestion, inhala- } \\
\text { tion absorption } \\
\text { through the skin }\end{array}$ & $\begin{array}{l}\text { Known human } \\
\text { carcinogen }\end{array}$ & Lung cancer, skin cancer and stomach cancer ${ }^{17)}$. \\
\hline Nickel & $1 \mathrm{mg} / \mathrm{m}^{3}$ & $15 \mu \mathrm{g} / \mathrm{m}^{3}$ & & $\begin{array}{l}\text { Inhalation and } \\
\text { skin contact }\end{array}$ & $\begin{array}{c}\text { Anticipated as } \\
\text { carcinogen }\end{array}$ & Skin rash, bronchitis, reduced lung function ${ }^{18)}$. \\
\hline Chromium $^{6+}$ & $0.1 \mathrm{mg} / \mathrm{m}^{3}$ & $1 \mu \mathrm{g} / \mathrm{m}^{3}$ & & $\begin{array}{l}\text { Breathing, inges- } \\
\text { tion, skin contact }\end{array}$ & $\begin{array}{l}\text { Chromium }^{6+} \text { in } \\
\text { a known human } \\
\text { carcinogen }\end{array}$ & $\begin{array}{l}\text { Runny nose, nosebleeds, ulcers and holes in the nasal } \\
\text { septum, stomach upsets and ulcers, convulsions, kid- } \\
\text { ney and liver damage, skin ulcers }{ }^{19)} \text {. }\end{array}$ \\
\hline
\end{tabular}




\section{Conclusions}

Gravimetric analysis of the concentration of aerosols in the breathing zone of the EDM operator was carried out and its variation with the process parameters was studied. The hazard potentials of the EDM process were identified using HAZOP. The causes and remedies of fire and emission hazards of this process were presented. Following were the major conclusions evolved from this study.

1. The effect of process parameters on concentration of aerosol showed that the emission from the EDM process increased with increase in the peak current, pulse duration \& dielectric level and decreased when the flushing pressure was increased.

2. At higher values of peak current and pulse duration, the concentration of aerosols at the breathing zone of the operator was just above the permissible exposure limit value for respirable particulates $\left(5 \mathrm{mg} / \mathrm{m}^{3}\right)$. However the limit values for particulates generated from the EDM process are not available.

3. HAZOP study of the EDM process with hydrocarbon based dielectric fluid reveals that this process is vulnerable to fire and explosion hazards. The fire hazard can be prevented by:

- using dielectric fluid of high flash point

- providing a spark arrestor around the dielectric tank

- providing a safety interlock to shut down the process when the temperature of the dielectric fluid rises to $15^{\circ} \mathrm{C}$ below its flash point

- providing automatic fire extinguishing system A detailed discussion on preventing fire hazard is presented in the previous section.

4. The toxic nature of the dielectric fluid and erosion of slurry has to be studied in detail in order to understand the possibility of contact dermatitis to the operators.

\section{Acknowledgements}

The authors are grateful to the Director, NIT Tiruchirappalli for providing the facilities to carry out the experimental work. Part of this work is supported by the Ministry of Environment and Forests, Government of India (F.No.19/102/2008-RE).

\section{References}

1) Ho KH, Newman ST (2003) State of the art electrical discharge machining (EDM). Int J Mach Tools Manuf 43, 1287-300.

2) Tonshoff HK, Egger R, Klocke F (1996) Environmental and safety aspects of electrophysical and electrochemical processes. Annals of CIRP Manufacturing Technology 45, 553-68.

3) Leao FN, Pashby IR (2004) A review on the use of environmentally-friendly dielectric fluids in electrical discharge machining. J Mater Process Technol 149, 341-6.

4) Evertz S, Dott W, Eisentraeger A (2006) Electrical discharge machining: Occupational hygienic characterization using emission based monitoring. Int $\mathrm{J}$ Hyg Environ Health 209, 423-34.

5) Abbas NM, Solomon DG, Bahari MF (2007) A review on current research trends in electrical discharge machining (EDM). Int J Mach Tools Manuf 47, 1214-28.

6) Yeo SH, Tan HC, New AK (1998) Assessment of waste streams in electric-discharge machining for environmental impact analysis. Proceedings of Institution of Mechanical Engineers 212(B), 393-401.

7) Centers for Disease Control and Prevention, NIOSH manual for analytical methods. http://www.cdc. gov/niosh/docs/2003-154/pdfs/0600.pdf. Accessed November 3, 2009.

8) Labovsky J, Svandova Z, Markos J, Jelemensky L (2007) Model-based HAZOP study of a real MTBE plant. J Loss Prev Process Ind 20, 230-7.

9) Tait JI (1994) Building on HAZOP (hazard and operability) studies to produce knowledge-based systems. In: IEE Colloquium on Knowledge-Based Systems for Safety Critical Applications, 2/1-2/5, IEE, London.

10) Guimaraes ACF, Lapa CMF (2006) Hazard and operability study using approximate reasoning in light water reactor passive systems. Nucl Eng Des 236, 1256-63.

11) Wong YS, Lim LC, Lee LC (1995) Effects of flushing on electro-discharge machined surfaces. J Mater Process Technol 48, 299-305.

12) Lonardo PM, Bruzzone AA (1999) Effect of flushing and electrode material on die sinking EDM. Annals of CIRP 48, 123-6.

13) Agency for Toxic Substances and Disease Registry (2007) Toxicological Profile for Benzene, U.S. Department of Health and Human Services, Public Health Service, Atlanta.

14) Agency for Toxic Substances and Disease Registry (2000) Toxicological Profile for Toluene, U.S. Department of Health and Human Services, Public Health Service, Atlanta.

15) Agency for Toxic Substances and Disease Registry (2007) Toxicological Profile for Ethylbenzene (Draft for Public Comment), U.S. Department of Public Health and Human Services, Public Health Service, 
Atlanta.

16) Agency for Toxic Substances and Disease Registry (2007) Toxicological Profile for Xylene, U.S. Department of Public Health and Human Services, Public Health Service, Atlanta.

17) Agency for Toxic Substances and Disease Registry (1995) Toxicological profile for polycyclic aromatic hydrocarbons, U.S. Department of Public Health and Human Services, Public Health Service, Atlanta.
18) Agency for Toxic Substances and Disease Registry (2005) Toxicological Profile for Nickel, U.S. Department of Public Health and Human Services, Public Health Service, Atlanta.

19) Agency for Toxic Substances and Disease Registry (2000) Toxicological Profile for Chromium, U.S. Department of Public Health and Human Services, Public Health Service, Atlanta. 